\title{
Age of onset of cannabis use and decision making under uncertainty
}

\author{
Jose Ramón Alameda-Bailén Corresp.., ${ }^{1}$ ， Pilar Salguero-Alcañiz ${ }^{1}$ ， Ana Merchán-Clavellino ${ }^{2}$, Susana Paíno-Quesada \\ 1 Basic Psychology, University of Huelva, Huelva, Spain \\ 2 Basic Psychology, Universsity of Cádiz, Puerto Real, Cádiz, Spain \\ 3 Personality, Evaluation and Psychological Treatments, University of Huelva, Huelva, Spain \\ Corresponding Author: Jose Ramón Alameda-Bailén \\ Email address: alameda@uhu.es
}

Objective: Cannabis, like other substances, negatively affects health, inducing respiratory problems and mental and cognitive alterations. Memory and learning disorders, as well as executive dysfunctions, are also neuropsychological disorders associated to cannabis use. Recent evidence reveals that cannabis use during adolescence may disrupt the normal development of the brain. This study is aimed to analyse possible differences between early-onset and late-onset cannabis consumers.

Method: We used a task based on a card game with four decks and different programs of gains/ losses. 72 subjects (19 women; 53 men) participated in the study; which were selected through a purposive samplingand divided into three groups: early-onset consumers, late-onset consumers, and control (nonconsumers). The task used was the "Cartas" program (computerized version based on the lowa Gambling Task -IGT-), with two versions: direct and inverse. The computational model "Prospect Valence Learning" (PVL) was applied in order to describe the decision according to four characteristics: utility, loss aversion, recency, and consistency.

Results: The results evidence worst performance in the IGT in the early-onset consumers as compared to late-onset consumers and control. Differences between groups were also found in the PVL computational model parameters, since the process of decision making of the early-onset consumers was more influenced by the magnitude of the gains-losses, and more determined by short-term results without loss aversion.

Conclusions: Early onset cannabis use may involve decision-making problems, and therefore intervention programs are necessary in order to reduce the prevalence and delay the onset of cannabis use among teenagers. 


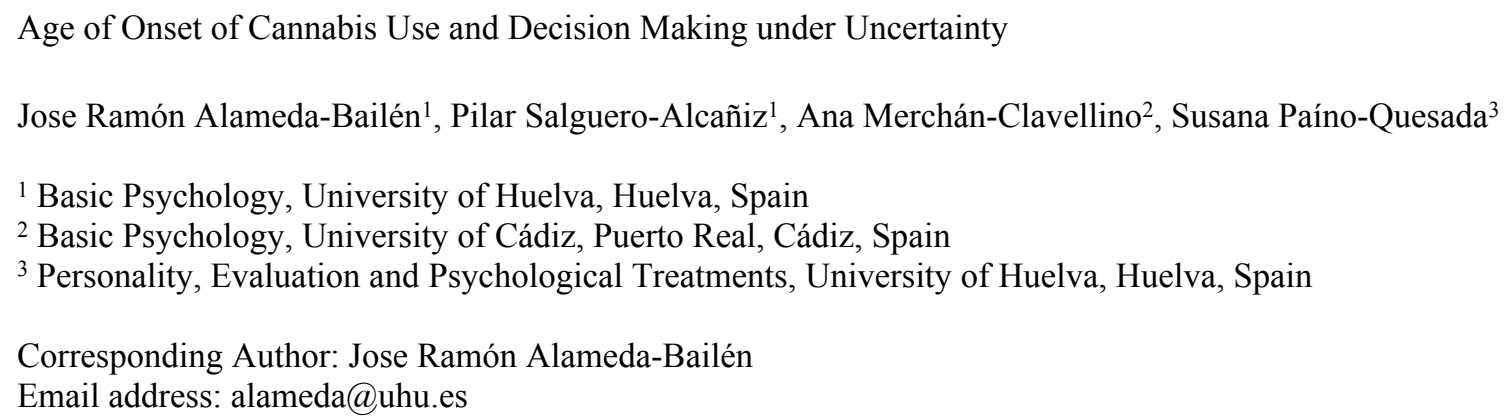

12 Abstract

13 Objective: Cannabis, like other substances, negatively affects health, inducing respiratory problems and mental and 14 cognitive alterations. Memory and learning disorders, as well as executive dysfunctions, are also neuropsychological disorders associated to cannabis use. Recent evidence reveals that cannabis use during adolescence may disrupt the 16 normal development of the brain. This study is aimed to analyse possible differences between early-onset and lateonset cannabis consumers.

Method: We used a task based on a card game with four decks and different programs of gains/ losses. 72 subjects (19 women; 53 men) participated in the study; which were selected through a purposive sampling and divided into three groups: early-onset consumers, late-onset consumers, and control (non-consumers). The task used was the "Cartas" program (computerized version based on the Iowa Gambling Task -IGT-), with two versions: direct and inverse. The computational model "Prospect Valence Learning" (PVL) was applied in order to describe the decision according to four characteristics: utility, loss aversion, recency, and consistency.

24 Results: The results evidence worst performance in the IGT in the early-onset consumers as compared to late-onset 25 consumers and control. Differences between groups were also found in the PVL computational model parameters, 26 since the process of decision making of the early-onset consumers was more influenced by the magnitude of the gainslosses, and more determined by short-term results without loss aversion.

28 Conclusions: Early onset cannabis use may involve decision-making problems, and therefore intervention programs are necessary in order to reduce the prevalence and delay the onset of cannabis use among teenagers. 
Introduction

According to the Spanish Observatory on Drugs and Drug Addiction (2015), cannabis is the most frequently consumed illegal substance in Spain, and the age of onset is also the earliest (18.6 years). The use of cannabis is considerably more extended among youth, and the highest incidence rates occur between 15 and 17 years, reaching $47.0 \%$ (OEDT, 2015). As the age of the population increases, the use cannabis decreases. cognitive alterations (psychosis, anxiety, dependence, etc.). Memory and learning disorders (Crane et al., 2013; Jager et al., 2006), and executive dysfunctions (Alameda, Paíno \& Mogedas, 2012; Alameda, Salguero, Merchán y Paíno, 2014; Crean, Crean \& Mason, 2011; Fontes et al., 2011), are also neuropsychological disorders related to cannabis use. There is some consensus about the determinants of the short and long-term consequences of cannabis use: age of onset of consumption, consumption frequency, consumption duration, the amount of tetrahydrocannabinol in the cannabis, etc. (Volkow et al., 2016). Among these factors, the age of onset of consumption is currently the most relevant, because the most recent empirical evidence reveals that cannabis use during adolescence may disrupt the normal development of the brain. Specifically, cannabis consumption during this period seems to affect specific brain maturation processes, such as synaptic pruning and the development of white matter, and therefore the alterations in these processes could lay the foundation for cognitive and mental health impairments in adulthood (Lubman, Cheetham \& Yücel, 2015).

These results are quite similar to those of other works that highlight that the age of cannabis use onset and the resulting consumption patterns contribute to the risk of suffering from mental illnesses, for example psychosis. In this respect, Di Forti et al. (2014) observed that there are substantial differences in the age of psychosis onset among consumers who began to use cannabis before age 15 and after that age. et al. (2011) highlighted that the early-onset group had worse performance than the late-onset group in attention tasks, impulse control, and executive function, and thus it can be concluded that regular consumption before age 15 can have adverse effects on neurocognitive functioning.

On another hand, Meier et al. (2012) showed in a longitudinal study that the greatest neuropsychological 
57 consumption. The results of Gruber et al. (2012) are congruent with these findings, as a worse performance in the executive functions (WAIS-R, Stroop, Wisconsin, etc.) was observed in cannabis consumers with onset before the age of 16 .

To sum up, evidence seems to support the idea that adolescence is a period of special risk, as cannabis use at this stage of development causes adverse reactions that are more severe and persistent than those related to consumption during adulthood. The neurotoxic damage of cannabis in the teenager brain could produce in these earlyonset consumers irreversible alterations to the mental health and the cognitive functions. the somatic marker hypothesis (Damasio, 1994), a research paradigm in which all the variations of the decisionmaking processes of the different communities are evaluated through the Iowa Gambling Task (IGT; Bechara et al., 1994). IGT simulates a card game that allows studying decision-making processes in uncertain situations of everyday life in the laboratory. Healthy individuals make more advantageous choices, however, orbitofrontal damaged patients and people with addictions, among others, tend to choose cards from the most disadvantageous decks and cannot anticipate the consequences of their choices because of their difficulties to develop emotional signals related to the affective value of the different choices (Alameda, Paíno \& Mogedas, 2012; Bechara, 2003; Bechara \& Damasio, 2002; Bechara et al., 1997; Bechara, Tranel \& Damasio, 2000; Mogedas \& Alameda, 2011). In people with addictions, these difficulties to anticipate the consequences of their choices can be a consequence of drugs use, but also the cause of initiating consumption. According to Bechara, Tranel \& Damasio (2000), and Gordillo et al. (2010), the results of the IGT may be due to three factors:

- Hypersensitivity to reward: the perspective of obtaining a large immediate reward is higher than any chance of loss in the future, and preference for the advantageous decks is related to high response times.

- Insensitivity to punishment: the perspective of a large loss does not invalidate any chance of obtaining

83 To determine which of these options is more likely, Bechara, Tranel \& Damasio (2000) proposed a version of IGT in

84 which losses now turn into gains, and vice-versa; that is, the gains/losses structure is reversed. Preference for 
85 advantageous decks in the reverse task is coherent with sensitivity to punishment and hypersensitivity to reward, depending on the levels of activation associated with losses and gains, respectively. However, the preference for the disadvantageous decks is consistent with insensitivity to consequences, as defended by Bechara, Tranel \& Damasio (2000), and higher response times, which is related to high levels of emotional activation. Although there are models (not based in IGT) that emphasize the importance of reward hypersensitivity, they reflect a pre-existing vulnerability for addictive behaviors (Alloy et al., 2009; Nusslock \& Alloy, 2017), and therefore reward hypersensitivity should lead to greater substance use and prospectively put an individual at risk for addiction. consistency). The PVL model, based on Bayesian logic, has three general assumptions (Ahn et al., 2008): The four PVL parameters and the equations to calculate them, are:

To rate a card:

where: $\alpha$ indicate that the person is more sensitive to feedback outcomes, whereas low values of $\alpha$ indicate low sensitivity to feedback outcomes.

-Loss aversion ( $\lambda$ ). This value determines sensitivity to losses compared to gains. A $\lambda$ value less than 1 indicates more sensitivity to gains than to losses, whereas a $\lambda$ value greater than 1 indicates more sensitivity to losses than to gains.

To create deck expectancy (E), for deck $j$ on trial $t$, the equation is:

$$
E_{j}(t)=A \cdot E_{j}(t-1)+\delta_{j}(t) \cdot u(t)
$$


112 Where $j$ refers to deck A, B, C, or D. $\delta j(t)$ is a dummy variable equal to 1 if deck $j$ was chosen on trial $t$, and otherwise 113 is $0 . A$ is the recency or learning rate parameter.

114 -Recency parameter $(\boldsymbol{A})$. Determines how much the past expectancy is discounted. When $A$ is close to 0 , more weight is granted to past outcomes, and when $A$ is close to 1 , more weight is granted to recent outcomes.

116 The equation to calculate the probability of choosing Deck $j$ is:

$$
\operatorname{Pr}[D(t+1)=j]=\frac{e^{\theta(t) \cdot e_{j}(t)}}{\sum_{K=1}^{4} e^{\theta(t) \cdot E_{k}(t)}}
$$

118

To calculate the consistency between choices and expectancies, the equation is:

$$
\theta(t)=3^{c}-1
$$

- Consistency or Response Sensitivity (c) is a consistency parameter (choice sensitivity), where low values denote a random sensitivity choice, whereas high values show a deterministic sensitivity choice.

Based on this background, this study aimed to analyse possible differences between early-onset and latemore risky decisions.

135 Method

136 Participants

137 All the participants were degree, Master's or Doctoral students, as well as University staff. We collected data on the 138 consumption of cannabis and other drugs in a group of 75 volunteers, to differentiate between the early and late onset 
139 cannabis use. Eighteen participants reported an age of onset of 16 years or less, and from this age we established the 140 size of the late onset and control group. The groups were matched by sex and education level, with no significant 141 differences in these variables. Nineteen women and 53 men, aged between 18-36 years, participated in this study.

142 They were divided into three groups ( $n=18$, early-onset cannabis users; $n=18$, late-onset cannabis users; $n=36$, 143 non-consumers as control group). Participants had not history of gambling problems, consumption of alcohol or other 144 significant drugs, and they were not under psychopharmacological treatment. All participants provided informed 145 consent to participate in the study. The procedure was carried out in accordance with the recommendations of ethics 146 guidelines of the University of Huelva and according to the Declaration of Helsinki

Since the groups were classified by age, we included the condition that the years of consumption and the 148 daily consume of cannabis cigarettes were not significantly different, otherwise the early-onset consumers would 149 always show more years of consumption than the late-onset consumers. The characteristics of the groups were: Early-onset cannabis consumers: 18 participants (5 women; 13 men), aged between 18-24 years ( $M=21, S D$

$152=2.01$ ). Four participants had elementary studies, five had secondary education and nine were university students.

153 The mean duration of consumption was 5.66 years $(S D=2.40)$, and consumption was 4.72 cannabis cigarettes per day $154(S D=2.89)$. We selected participants with an age of onset of cannabis use between 14 and 16 years $(M=15.3, S D=$ $1550.88)$.

Late-onset cannabis consumers: 18 participants (4 women; 14 men), aged between 21-36 years $(M=27.55$,

$157 S D=3.80$ ). Five participants had elementary studies, five had secondary education and eight were university students.

158 The mean duration of consumption was 4.16 years $(S D=2.70)$, and consumption was 3.83 cannabis cigarettes per day $159(S D=2.75)$. There were no significant differences either in the duration of consumption or in the amount consumed,

160 between the consumer groups $(p>.05)$. We selected participants with an age of onset of cannabis use between 20 and 16128 years $(M=23.3, S D=3.12)$.

162 Control group: 36 participants (10 women; 26 men), aged between 19-36 years $(M=24.69, S D=4.21)$. Nine

163 participants had elementary studies, eleven had finished secondary education, and sixteen were university graduates.

164 As the mean age of the consumption groups (early/late-onset) was different, the control group had twice the number 165 of participants to match the ages of each group. In addition, we found that there were no significant differences in any 166 of the study variables, based on the age of the control group. 
167 Task

The software "Cartas" (Palacios et al., 2010), a computerised version of the Iowa Gambling Task (Bechara et al., 1994), was used to assess the decision-making process. The "Cartas" task simulates a card game in which the individual must choose from four decks across different trials (Figure 1 and Table 1). may be larger losses (approximately, in 30 plays out of 100), until they switch the strategy and start to select decks that are more beneficial at the long-term, that is, those with less gain but also with less loss (Martínez-Selva et al., 2006). The task starts with imaginary $2000 €$, and the participants must try to either increase this amount or retain it, across 100 plays. A reverse task (EFGH version), in which A-B decks become advantageous and C-D decks become disadvantageous, was also used in the present study. In the reverse version, the game is based on frequent losses and occasional gains.

Procedure

180 The participants were informed of the objectives of the study and they voluntarily participated in a single individual 15-20-minute session. Before starting the task, data about age, sex, educational level, and drug use (onset age and the daily amount consumed) were collected. Participants performed both the classic and the reverse version of the task.

183 This procedure was conducted in a room provided with all the necessary tools to the study. After completion the study, 184 an explanation of the obtained results was provided to all participants under request. Participants were informed that 185 the task objective was to increase start-up money, but they would not be rewarded with real money, as data show that 186 there is no difference in IGT performance when using real and fictitious money (Bowman \& Turnbull, 2003), or when 187 participants can keep all or part of the gains (Bickel et al., 2009; Carter \& Pasqualini, 2004, Fernie \& Tunney, 2006; 188 Schmitt, Brinkley, \& Newman, 1999; Suzuki et al., 2003). SPSS software was used to analyse data of the PVL model of IGT. The dependent variables used were:

- Percentage of advantageous / disadvantageous choices: Choices made in 100 trials, and the partial percentages in five blocks of 20 trials (blocks B1: trial 1 to 20, B2: 21-40, B3: 41-60, B4: 61-80, \& B5: 81$100)$, both in the classic and the reverse task. 
- The number of cards chosen in each deck (A, B, C, D) in both versions of the task.

198

- The time spent in the selection of the different groups for the advantageous and disadvantageous choices in the reverse version options.

200

- The PVL parameters: $\alpha$ (utility rule), $\lambda$ (loss aversion), A (recency), $c$ (consistency) were calculated through

201 a $R$ script, using the maximum likelihood method, MLE (Ahn et al., 2008), and the decay-rule (Erev \& Roth, 1998), as it consistently shows better models of post-hoc fit than the delta-rule (Rescorla \& Wagner, 1972) with respect to the IGT (Yechiam et al., 2005).

204 The independent variable used was the age at onset of cannabis use. The influence of variables such as sex,

205

206

207

208

209

210

\section{1}

212

213

214

215

216

217

218

219

220

221 age, educational level, daily consumed cannabis cigarettes, and years of consumption was also analysed. To analyse the influence of consumption on task performance and the parameters of the PVL model, Student's $t$-tests for independent samples were calculated, comparing the results according to cannabis use. To compare the evolution across the different blocks in each group, repeated measures analyses of variance were used.

Results

\section{Normal Procedure}

The control group made advantageous choices on $60.94 \%(S D=5.65,95 \%$ CI $[57.8,64.1])$ in the total IGT $(\mathrm{IG}=$ $21.34)$, and the late-onset group made $49.78 \%(S D=13.07,95 \%$ CI $[45.3,54.2]$ IG $=-0.44)$ but there were no significant differences $(\mathrm{t}(1,17)=0.072 ; \mathrm{p}=.943,95 \%$ CI $[12.5,13.4])$. The early-onset group made advantageous choices on $32.78 \%(S D=11.22,95 \% \mathrm{CI}[28.3,37.2] \mathrm{IG}=-34.44)$, the differences between this group and the control group $(\mathrm{t}(1,35)=11.619 ; \mathrm{p}=.000,95 \% \mathrm{CI}[18.1,25.7])$ and the late-onset group $(\mathrm{t}(1,17)=6.508 ; \mathrm{p}=.000,95 \% \mathrm{CI}$ $[23.2,45.6])$ were significant. Figure 2 shows the advantageous/disadvantageous choices of the different groups.

The between-group differences observed in the percentages of elections were significant $(F(2,71)=53.48, p$ $\left.=.000, \eta_{\mathrm{p}}^{2}=.608\right)$. Bonferroni-corrected paired comparisons also showed significant differences between the control and early-onset groups $(\mathrm{p}=.000,95 \% \mathrm{CI}[21.5,34.9])$, the control and late-onset groups $(\mathrm{p}=.000,95 \%$ CI $[45.0$, 17.9]), and the late-onset and early-onset groups $(\mathrm{p}=.000,95 \% \mathrm{CI}[9.3,24.7])$

Figure 2 
choices throughout the five blocks (Table 2 and Figure 3), whereas the advantageous choices were detected in the

225

226

227

228

229

230

231

232

234

235

236

237

238

239

240

241

242

243

244

245

246

247

248 249 third block in the late-onset group, with an increasing trend to such choices. The control group showed an increasing trend to advantageous choices in the second block.

Table 2 Figure 3) showed significant differences between the early-onset consumers and the other two groups in the B1. In the B2 there were significant differences between the control group and the early-onset consumers. In the B3 there were significant differences between the early-onset consumers and the control group, and between the early-onset and late-onset consumers. In the B4 there were significant differences between both groups of consumers, and between the control and consumer groups (early and late onset). In the B5, significant differences were observed between consumers and the control group.

\section{Figure 3}

Repeated measures ANOVA revealed differences in the scores of the different blocks $(\mathrm{F}(4,68)=13,943, \mathrm{p}$ $\left.=.000, \eta_{\mathrm{p}}^{2}=.451\right)$. Analysing each group independently, the early-onset group showed significant differences between blocks $\left(F(4,14)=4.546 ; p=.015, \eta_{\mathrm{p}}^{2}=.565\right)$, and Bonferroni-corrected comparisons showed significant differences between B1 and B5 ( $p=.010,95 \%$ CI $[3.0,29.2]))$. Comparisons revealed that there were no differences in the late-onset consumers $\left(F(4,14)=1.804 ; p=.184, \eta_{\mathrm{p}}{ }^{2}=.340\right)$ and therefore the slight increasing trend was not confirmed in this group. Finally, in the control group, significant differences were observed across the blocks $(F(4,32)$ $=11.623 ; p=.000, \eta_{\mathrm{p}}^{2}=.592$ ). Bonferroni-corrected comparisons revealed significant differences between $\mathrm{B} 1$ and the other blocks (B1-B2, $p=.008,95 \%$ CI $[3.3,32.2])$; B1-B3, $p=.011,95 \%$ CI $[2.9,34.6]$; B1-B4, $p=.000,95 \%$ CI $[13.5,40.7]$ and B1-B5, $p=.000,95 \%$ CI $[16.2,41.8])$, and between B2-B5, (p = .036, 95\% CI [0.5, 22.0]).

Table 3 shows the results obtained for the parameters of the PVL model, where no significant differences were found between the groups in consistency $(\mathrm{c}: \mathrm{F}(2,69)=0.804, \mathrm{p}=.452)$, with values in each group close to 1 . These results indicate little coherence between expectations and the final choice, that is, the choice of the deck was random. 
Table 3

There were significant differences in the factor group in loss aversion $(\lambda: F(2,69)=15.414, p=.000)$. In

252

253

254

255

256

257

258

259

260

261

262

263

264

265

266

267

268

269

270

271

272

273

274

275

276

277

early-onset consumers, $\lambda$ value was close to 0 , which indicates that this group perceived losses as neutral events, that is, this group showed more sensitivity to gains than to losses, and there was no loss aversion. In late-onset consumers, $\lambda$ value was close to 1 , which suggests that losses and gains were considered equally, whereas in the control group, $\lambda$ value was greater than 1, indicating more sensitivity to losses than to gains, and loss aversion (Figure 4).

Regarding the shape of the utility function $(\alpha: \mathrm{F}(2,69)=12.258, \mathrm{p}=.000)$, the early-onset and late-onset consumers showed a $\boldsymbol{\alpha}$ value close to 1, suggesting that their choices were more sensitive to feedback outcomes, whereas in the control group, the $\boldsymbol{\alpha}$ value indicated a low sensitivity to feedback outcomes.

The early-onset consumers showed higher values in recency $(A: \mathrm{F}(2,69)=3.743, \mathrm{p}=.029)$, close to 1 , which suggests that the value of the last card had a large influence on the expectation created by that deck, and consequently all the previous choices were forgotten, and more weight was granted to recent outcomes. However, in the control group and the late-onset consumers, with $A$ scores close to 0 , the value of the previous performance had little influence on the expectation created by the decks, with previous experiences prevailing, so forgetting was a slower process, and more weight was granted to past outcomes.

\section{Inverse procedure}

The results observed in the classic version (ABCD) of the IGT may be due to hypersensitivity to reward, insensitivity to punishment, or insensitivity to future consequences (Bechara, Tranel \& Damasio, 2000). Preference in the reverse task for the disadvantageous decks is related to insensitivity to punishment when low response times are obtained and to hypersensitivity to reward with high response times (Gordillo et al., 2010). Preference for the unfavourable decks is consistent with insensitivity to consequences (Gordillo et al., 2010), which is the option argued by Bechara, Tranel \& Damasio (2000).

In the total IGT-inverse performance, the control group made advantageous choices on $51 \%(S D=16.70$, $95 \% \mathrm{CI}[45.3,56.0] \mathrm{IG}=2)$, versus $54.72 \%(S D=14.54,95 \% \mathrm{CI}[47.2,62.3] \mathrm{IG}=9.44)$ of the late-onset group and $42.722 \%(S D=10.77,95 \%$ CI $[34.7,49.8] \mathrm{IG}=-14.556)$ of the early-onset group. Comparing the results obtained in the inverse task with the normal task, we observe that late-onset consumers improve in their advantageous choices, 
278

279

280

281

282

283

284

285

286

287

288

289

290

291

292

293

294

295

296

297

298

299

300

301

302

303

304

going from $32.78 \%$ to $42.72 \%$, resulting in this significant increase $(t(1,17)=3.779, \mathrm{p}=.001)$, although again this group showed the lowest scores, predominantly with disadvantageous choices. The late-onset group also increase their advantageous choices, going from $49.78 \%$ to $54.72 \%$, but this increase is not significant $(\mathrm{t}(1,17)=1.953, \mathrm{p}=.067)$, while the control group decrease your advantageous choices, going from $60.94 \%$ to $51 \%(\mathrm{t}(1,35)=4.666, \mathrm{p}=.000)$.

The differences observed in the percentages of advantageous choices of inverse task were not significant ( $\mathrm{F}$ $\left.(2,71)=2.903, \mathrm{p}=.062, \eta_{\mathrm{p}}{ }^{2}=.078\right)$. The Bonferroni-corrected comparisons showed no significant differences $(\mathrm{p}>$ $.05)$.

Table 4 shows the descriptive statistics for the different blocks of the reverse task. Differences between the early-onset and late-onset consumers were found only in the B3.

Table 4

In the task evolution (Figure 5), a declining trend in the late-onset consumers was found, whereas the earlyonset consumers also showed a declining trend in the first block, and an increasing trend in the last block, but when the task was completed, there were fewer advantageous choices than those made at the beginning. The control group showed an increasing tendency in the three first blocks. However, these trends were not confirmed by the repeated measures ANOVA $\left(\mathrm{F}(4,67)=0.296, \mathrm{p}=.880, \eta_{\mathrm{p}}{ }^{2}=.017\right)$, because no significant between-group differences were found in the evolution of the task.

Figure 5

With respect to the parameters of the PVL model (Table 5), no significant differences in any of the parameters were found for the different groups, indicating a similar performance in each group. Very high $\lambda$ values were obtained in all the groups, which seems to confirm loss aversion. The shape of the utility showed values tending towards 1 in all the groups, suggesting that the choices were conditioned by the gains-losses magnitude. With respect to recency $(A)$, the values of all the groups were close to 0 , indicating that the last choice made did not affect the next one, forgetting was more gradual, and previous experiences prevailed. The consistency parameters $(c)$ revealed random choices.

Table 5

Figure 6 shows the response times of the consumer groups and the control group in the IGT, with higher response times for consumers in the advantageous choices.

Peer] reviewing PDF | (2018:01:23083:2:0:NEW 8 Jun 2018) 
305

306

307

308

309

310

311

312

313

314

315

316

317

318

319

320

321

322

323

324

325

326

327

328

329

330

331

332

Figure 6

No significant differences were found respect to the sex, age, educational level, daily consumption and years of consumption factors, in both versions of the task.

Discussion

In the classic procedure of the task, cannabis consumers obtained worse results than the control group, both in the set of the task and in the evolution of the task, with early-onset consumers obtaining the worst results. The control group and late-onset consumers started the task with similar values, and with the passage of time the control group increased their scores much more than the late-onset consumers, whereas the early-onset consumers showed lower percentages of advantageous choices. The performance of the early-onset consumers was worse, which indicates that the control group and the late-onset consumers were more efficient in the examination of the characteristics of the previous four decks (Dunn, Dalgleish \& Lawrence, 2006). Performance of consumers was better in the reverse task compared to the normal task, but this finding was no found in the control group. In the PVL parameters of the classic task, no differences were observed between the early-onset and late-onset consumers. Significant differences were found in the parameters $A, \alpha$ and $\lambda$ between the control group and the early-onset consumers. Significant differences in $\lambda$ values were also found between the control group and the late-onset consumers. In the inverse task, there were no significant differences in any of the PVL parameters.

The performance of the control group showed a favourable pattern of the decision-making process in the classic task, whereas this increase was lower in the consumers. The early-onset consumers always made more disadvantageous choices than advantageous. However, the late-onset consumers showed more advantageous choices from the third block, although choices were always lower than those of the control group. These results are congruent with other works that found a relationship between drug use and alterations in the decision-making process (Ahn et al., 2008, 2011, 2014; Alameda, Paíno \& Mogedas, 2012; Bechara \& Damasio, 2002; Bechara, Dolan \& Hindes, 2002; Bechara, et al., 2001; Bolla et al., 2005; Grant, Conttoreggi \& London, 2000; Mogedas \& Alameda, 2011; Vélez, Borja \& Ostrosky-Solís, 2010; Whitlow et al., 2004).

It can be concluded that the control group "learned" how the test works, and from the first block they showed their preference for the advantageous decks. On the contrary, cannabis users spent more time trying to distinguish the positive-negative characteristics of the different decks, probably due to their difficulty to use emotional signals when 
333 they must evaluate different response options. This limitation makes the task of assessing the positive-negative effects

334 of the choices more difficult, causing either hypersensitivity to instant reward or insensitivity to punishment, according

335 to Bechara \& Damasio (2002), and Damasio (1994). Our results coincide in revealing hypersensitivity to instant

336 reward (insensitivity to punishment) in late-onset consumers, although we also observed insensitivity to future

337 consequences in early-onset consumers, which may be related to work memory or impulsiveness alterations. On the

338 other hand, we did not find reward hypersensitivity in any of the groups (Alloy et al., 2009; Nusslock \& Alloy, 2017).

339 Other authors suggest that the above mentioned decision-making alterations are due the difficulty to establish

340 stimulus-reward relationships or to eradicate previously learnt responses. That is, consumers have problems reverting

341 former learning, which could modify or eradicate responses to environmental contingencies that were previously

342 rewarded (Maia \& McClelland, 2004; Rolls, 2004). This limitation may explain the different evolution of the choices

343 of the disadvantageous decks that offer gains at the beginning but imply losses in the long term. Thus, the control

344 group could have modified their initial perception as of the first block, and the late-onset consumers as of the third

345 block, but this did not occur in the early-onset consumers. This shows that consumers, especially those of the early-

346 onset group, either did not adequately identify the characteristics of the decks (Fernie \& Tunney, 2006; Lin et al.,

347 2007; Lin, Chiu \& Huang, 2009) or they had problems eradicating their initial preference for the disadvantageous

348 decks (A-B).

349 Our findings are related to the characteristics of the decision-making process in the PVL model (Table 4). In

350 this sense, early-onset consumers showed less consistency, that is, lower $c$ values, which implies higher randomness

351 of choices and more influence of the previous choice, as revealed by the highest values of $A$ (Ahn et al., 2008; Erev

$352 \&$ Barron, 2005). Moreover, regarding $\alpha$ values, the early-onset consumers showed a large magnitude of gains-losses,

353 whereas frequency was more important in the control group, and the late-onset consumers were in an intermediate

354 position. Alameda et al. (2014) and Fridberg et al. (2010) have reported similar results. With respect to the $\lambda$ values,

355 we found some significant differences between groups, with lower values in the consumers. That is, the early-onset

356 consumers perceived the losses as a neutral element, the late-onset consumers considered the gains and losses as

357 equals, and in the control group there was loss aversion, which is partly coherent with previous findings (Fridberg et

358 al., 2010) because Alameda et al. (2014) obtained the opposite results, that is, loss aversion in consumers but not in

359 the control group.

360 To sum up, through the PVL model, we can distinguish the different cognitive mechanisms of this model in 
361 the decision-making process. Thus, the decision-making process of the early-onset cannabis consumers was more

362 influenced by the magnitude of the gains/losses, more determined by the short-term results, and without loss aversion.

363 On the contrary, the performance of the control group was determined by the frequency of gains/losses, the long-term

364 influence of the results, and loss aversion. These results show quantitative differences regarding the cognitive 365 mechanisms, essentially between the different types of consumers, because they reveal worse results in the early-onset

366 consumers than in the late-onset consumers. In addition, our results indicate quantitative and qualitative differences

367 between the two types of consumers and the control group.

368 We also have observed that performance of the consumers was better in the reverse procedure than in the

369 normal procedure, whereas the control group performed the reverse task worse than the classic task. However, we

370 found few differences between groups. These findings coincide with those of other studies (Alameda et al., 2012,

371 2014; Mogedas \& Alameda, 2011).

372 In the PVL parameters of the reverse task, no significant differences were found between groups. Therefore,

373 the decision-making processes in both the consumers and the control group seem to be determined by the outcomes

374 feedback and a random sensitivity choice, and in these processes more weight is granted to past outcomes and more 375 sensitivity is shown to losses compared to gains.

376 Unlike the proposals of Bechara, Tranel \& Damasio (2000), and Gordillo et al. (2010), the analysis of the

377 choices made with respect to response times showed insensitivity to future consequences in the early-onset consumers,

378 due to their preference for the disadvantageous decks, suggesting that, in this group, there are some difficulties to use

379 immediate prospects as a guide. Late-onset consumers showed a preference for the favourable decks, with high

380 response times, and thus they expressed hypersensitivity to reward, that is, the perspective of receiving a large, instant

381 reward was higher than any chance of obtaining a future loss. The control group showed a preference for favourable

382 decks with low response times, which suggests insensitivity to punishment and that the prospect of large losses does

383 not offset any chance of gain.

384 Recent studies support the idea that cannabis use during adolescence can lead to more serious and long-

385 lasting consequences. The cannabis use may affect the endocannabinoid system, which plays an important role in the

386 brain development. This system could be altered by exogenous cannabinoids that affect its processes, specifically the

387 development of white matter (Solowij et al., 2011) and synaptic pruning (Bossong \& Niesink, 2010). Both processes

388 are considered critical for the brain development during adolescence. The endocannabinoid system inhibits the release 
389 of glutamate, and this process is modified by the action of exogenous cannabinoids, causing alterations in synaptic 390 pruning and interrupting the prefrontal cortex development. This effect would lead to a general disinhibition of the 391 prefrontal cortex functions, which, indeed, shares many of the cognitive disorders related to long-term cannabis use.

392 Depending on the dose and the duration, cannabis use could also contribute to the development of psychosis or 393 schizophrenia (Bossong \& Niesink, 2010; Caballero \& Tseng, 2012). This possibility is congruent with some results

394 indicating that the deficit in the decision-making process may be related to consumers' unusual functioning of the 395 prefrontal cortex regions, especially the orbitofrontal cortex (Bechara, 2003; Fridberg et al., 2010; Withlow et al., 396 2004).

397

398

399

400

401

402

403

404

405

406

407

408

409

410

411

412

413

414

415

416

417

\section{Conclusions}

Cannabis consumption in adolescence should be considered as a public health problem, extending to different fields, ranging from psychosis (Di Forti et al., 2014) to neurocognitive disorders such as learning and memory, executive functions, attention, impulse control disorders, etc. (Crean, Crean \& Mason, 2011; Fontes et al., 2011; Gruber et al., 2012; Solowij \& Battisti, 2008; Solowij et al., 2002). In addition, the damage produced by cannabis use in the teenager brain might be permanent, that is, some altered cognitive functions might not get to recover after the withdrawal of consumption (Meier et al., 2012).

The evidence of the adverse and irreversible effects of cannabis in the teenager brain may have social implications (Lubman, Cheetham \& Yücel, 2015). Early intervention programs to reduce the prevalence and delay the onset of cannabis use among teenagers are needed. Active policies are needed in order to combat the trivialization of cannabis use, basically during adolescence because the effects of cannabis on the developing brain are not comparable to the effects of this drug on a mature brain, considering that the cannabis modifies the neuromaturation and, therefore, the consequences could be irreversible.

According to the results of the present study and other studies, future investigations with larger samples seem necessary to address aspects such as time and quantity of consumption, withdrawal periods, number of relapses, and poly-consumption.

Related to the task, it would be important to have more reliable and less predictable measures, adjust the scheduling of the decks (Alameda, Paíno y Mogedas, 2012; Alameda et al., 2014; Contreras et al., 2008; Mogedas \& Alameda, 2011, van den Bos, Houx, \& Spruijt, 2006), use presentations with more intuitive stimuli (Gordillo et al., 
418 2010), analyse the type of instruction (Balodis, MacDonald \& Olmstead, 2006; DeDonno \& Demaree, 2008, Fernie 419 \& Tunney, 2006).

420 As for the probabilistic models, it would be interesting to expand with the PVL simulation processes, as for 421 example the PVL-delta (Ahn et al., 2008), the PVL-decay (Ahn et al., 2011, 2014), and the most recent Value-Plus422 Perseverance, VPP (Worthy, Pang \& Byrne, 2013). It would also be of interest to analyse neuroanatomical aspects of 423 decision making (He et al., 2016; Polaina et al., 2015).

424 Finally, highlighting the limitations of this work, as we discussed earlier, increasing the size of the sample,

controlling withdrawal periods, number of relapses or poly-consumption are important aspects, but perhaps the greatest limitation of this type of work is that they do not clarify the circular relationship that is established between are due to the neurotoxicity of the drugs or, problems in the decision making explain the beginning of consumption, an aspect that could only be elucidated with longitudinal studies.

\section{REFERENCES}

432 Ahn WY, Busemeyer JR, Wagenmakers EJ, Stout JC. 2008. Comparison of decision learning model using the generalization criterion method. Cognitive Science 32:1376-1402.

434 Ahn WY, Krawitz A, Kim W, Busemeyer JR, Brown JW. 2011. A model-based fMRI analysis with hierarchical Bayesian parameter estimation. Journal of Neuroscience Psychology Economics 4: 95-110. doi:

Ahn WY, Vasilev G., Lee SH, Busemeyer JR, Kruschke JK, Bechara A, Vassileva J. 2014. Decision making in stimulant and opiate addicts in protracted abstinence: Evidence from computational modeling with pure users. Frontiers in Psychology 5:849. doi: 10.3389/fpsyg.2014.00849

Alameda JR, Salguero MP, Merchán A, Paíno S. 2014. Mecanismos cognitivos en la toma de decisiones arriesgadas en consumidores de cannabis. Adicciones 26(2):146-158. in Decision-Making in Patients With Mild Alzheimer Disease. Current Alzheimer Research 14(12): 1248.

445 Alloy LB, Bender RE, Wagner CA, Whitehouse WG, Abramson LY, Hogan ME, Harmon-Jones E. 2009. Bipolar 
446

447

448

449

450

451

452

453

454

455

456

457

458

459

460

461

462

463

464

465

466

467

468

469

470

471

472

473

spectrum-substance use co-occurrence: behavioral approach system (BAS) sensitivity and impulsiveness as shared personality vulnerabilities. Journal of Personality and Social Psychology 97:549-565. doi: $10.1037 / \mathrm{a} 0016061$

Balodis IM, MacDonald TK, Olmstead MC. 2006. Instructional cues modify performance on the Iowa Gambling Task. Brain and Cognition 60:109-117. doi: 10.1016/j.bandc.2005.05.007

Bechara A. 2003. Risky business: Emotion decision making and addiction. Journal of Gambling Studies 19:102-103. doi: 10.1023/A:1021223113233

Bechara A, Damasio H. 2002. Decision-making and addiction (part. I): Impaired activation of somatic states in substance dependent individuals when pondering decisions with negative future consequences. Neuropsychologia 40:1675-1689.

Bechara A, Dolan S, Hindes A. 2002. Decision-making and addiction (part. II): Myopia for the future or hypersensitivity to reward? Neuropsychologia 40:1690-1705.

Bechara A, Damasio AR, Damasio H, Anderson SW. 1994. Insensitivity to future consequences following damage to human prefrontal cortex. Cognition 50:7-15. doi: 10.1016/0010-0277(94)90018-3

Bechara A, Damasio H, Tranel D, Damasio AR. 1997. Deciding advantageously before knowing the advantageous strategy. Science 275:1293-1295.

Bechara A, Dolan S, Denburg N, Hindes A, Anderson SW, Nathan PE. 2001. Decision making deficits linked to a dysfunctional ventromedial prefrontal cortex revealed in alcohol and stimulant abusers. Neuropsychologia 39:376-389.

Bechara A, Tranel D, Damasio H. 2000. Characterization of the decision-making deficit of patients with ventromedial prefrontal cortex lesions. Brain 123:2189-2202.

Bickel WK, Pitcock JA, Yi R, Angtuaco EJ. 2009. Congruence of BOLD response across intertemporal choice conditions: fictive and real money gains and losses. Journal of Neuroscience 29:8839-8846. doi: 10.1523/JNEUROSCI.5319-08.2009

Bolla KI, Eldreth DA, Matochik JA, Cadet JL. 2005. Neural substrates of faulty decision-making in abstinent marijuana users. Neuroimage 29:480-492. doi: 10.1016/j.neuroimage.2005.02.012

Bos R, van den Houx BB, Spruijt BM. 2006. The effect of reward magnitude differences on choosing disadvantageous decks in the Iowa Gambling Task. Biologycal Psychology 71:155-161.

Peer] reviewing PDF | (2018:01:23083:2:0:NEW 8 Jun 2018) 
474 Bossong MG, Niesink RJ. 2010. Adolescent brain maturation the endogenous cannabinoid system and the neurobiology of cannabis-induced schizophrenia. Progress in Neurobiology 92(3):370-385.

476 Bowman CH, Turnbull OH. 2004. Emotion-based learning on a simplified card task: the Iowa and Bangor Gambling tasks. Brain and Cognition 53:277-282. doi: 10.1016/j.bandc.2004.02.009

478

479

480

481

482

483

484

485

486

487

488

489

490

491

492

493

494

495

496

497

498

499

500

501

Caballero A, Tseng KY. 2012. Association of cannabis use during adolescence prefrontal CB1 receptor signaling and schizophrenia. Frontiers in Pharmacology 3:101.

Carter S, Pascualini MS. 2004. Stronger autonomic response accompanies better learning: A test of Damasio's somatic marker hypothesis. Cognition and Emotion 18:901-911.

Contreras D, Catena A, Cándido A, Perales JC, Maldonado A. 2008. Funciones de la corteza prefrontal ventromedial en la toma de decisiones emocionales. Internacional Journal of Clinical and Health Psychology 8:285-313.r

Crane NA, Schuster RM, Fusar-Poli P, Gonzalez R. 2013. Effects of cannabis on neurocognitive functioning: recent advances neurodevelopmental influences and sex differences. Neuropsychology Review 23(2):117-137. doi: $10.1007 / \mathrm{s} 11065-012-9222-1$

Crean RD, Crane NA, Mason BJ. 2011. An evidence-based review of acute and long-term effects of cannabis use on executive functions. Journal of Addiction Medicine 5(1):1-8.

Damasio AR. 1994. Descartes' Error. New York: Avon Books.

DeDonno MA, Demaree HA. 2008. Perceived time pressure and the Iowa Gambling Task. Judgment and Decision Making 3:636-640.

Di Forti M, Sallis H, Allegri F, Trotta A, Ferraro L, Stilo SA, Marconi, A, La Cascia, C, Reis, T, Pariante, C, Dazzan P, Mondelli V, Paparelli, A, Kolliakou, A, Prata, D, Gaughran, F, David AS, Morgan, C, Stahl D, Khondoker, M, MacCabe, JH \& Murray RM, 2014. Daily use especially of high-potency cannabis drives the earlier onset of psychosis in cannabis users. Schizophrenia Bulletin 40(6):1509-1517. doi:10.1093/schbul/sbt181

Dunn BD, Dalgleish T, Lawrence AD. 2006. The somatic marker hypothesis: A critical evaluation. Neuroscience and Biobehavioral Reviews 30:239-71.

Erev I \& Barron G. 2005. On adaptation maximization and reinforcement learning among cognitive strategies. Psychological Review 112: 912-931.

Erev I \& Roth AE. 1998. Predicting how people play games: Reinforcement learning in experimental games with unique mixed strategy equilibria. American Economic Review 88: 848-881. 
502 Fernie G \& Tunney RJ. 2006. Some decks are better than others: The effect of reinforcer type and task instructions on 503 learning in the Iowa Gambling Task. Brain and Cognition 60:94-102. doi: 10.1016/j.bandc.2005.09.011

504 Fontes MA, Bolla KI, Cunha PJ, Almeida PP, Jungerman F, Ramos Laranjeira R, Bressan RA \& Lacerda ALT. 2011.

$505 \quad$ Cannabis use before age 15 and subsequent executive functioning. The British Journal of Psychiatry 198:42-

$506 \quad$ 447. doi: 10.1192/bjp.bp. 110.077479

507 Fridberg DJ, Queller S, Ahn W, Kim W, Bishara A, Busemeyer JR, Porrino L \& Stout JC. 2010. Cognitive 508 mechanisms underlying risky decision-making in chronic cannabis users. Journal of Mathematical 509 Psychology 54:28-38. doi: 10.1016/j.jmp.2009.10.002.

Gordillo F, Salvador J, Arana JM, Mestas L, Meilán JJG, Carro J \& Pérez E. 2010. Estudio de la toma de decisiones en una variante de la Iowa Gambling Task. Revista Electrónica de Motivación y Emoción 34.

512 Grant S, Conttoreggi C \& London ED. 2000. Drug abusers show impaired performance in a laboratory test of decisionmaking. Neuropsychologia 38:1180-1187.

514 Gruber SA, Sagar KA, Dahlgren MK, Racine M \& Lukas SE. 2012. Age of onset of marijuana use and executive function. Psychology of Addictive Behaviors 26(3):496-506. doi:10.1037/a0026269

516

517

518

519

520

521

522

523

524

525

526

527

528

529

Gruber SA, Rogowska J \& Yurgelun-Todd D. 2009. Altered affective response in marijuana smokers: An FMRI study. Drug and Alcohol Dependence 105:139-153.doi: 10.1016/j.drugalcdep.2009.06.019

He Q, Chen M, Chen C, Xue G, Feng T \& Bechara A. 2016. Anodal Stimulation of the Left DLPFC Increases IGT Scores and Decreases Delay Discounting Rate in Healthy Males. Frontiers in Psichology 7:1421. doi: 10.3389/fpsyg.2016.01421

Jager G, Kahn RS, van den Brink W, van Ree RM \& Ramsey NF. 2006. Long-term effects of frequent cannabis use on working memory an attention: An fMRI study. Psychopharmacology 185:358-368.

Lin CH, Chiu YC, Lee PL \& Hsieh JC. 2007. Is deck B a disadvantageous deck in the Iowa Gambling Task?” Behavioral and Brain Function 3:16. doi: 10.1186/1744-9081-3-16

Lin CH, Chiu YC \& Huang JT. 2009. Gain-loss frequency and final outcome in the Soochow Gambling Task: A reassessment. Behavioral and Brain Function 5:45. doi: 10.1186/1744-9081-5-45

Lubman DI, Cheetham A \& Yücel M. 2015. Cannabis and adolescent brain development. Pharmacology Therapeutics 148:1-16.

Maia TV \& McClelland JL. 2004. A reexamination of the evidence for the somatic marker hypothesis: What 
participants really know in the Iowa gambling task. Proceedings of National Academy of Sciences of the United States of America (PNAS) 101:16075-16080.

532

533

534

535

536

537

538

539

540

541

542

543

544

545

546

547

548

549

550

551

552

553

554

555

556

557

Martínez-Selva JM, Sánchez-Navarro JP, Bechara A \& Román F. 2006. Brain mechanisms involved in decision making. Revista de Neurología 42:411-418.

Meier MH, Caspi A, Ambler A, Harrington H, Houts R, Keefe RSE, McDonald K, Ward A, Poulton R \& Moffitt TE. 2012. Persistent cannabis users show neuropsychological decline from childhood to midlife. Proceedings of the National Academy of Sciences of the United States of America (PNAS) 109(40): E2657-E2664. doi:10.1073/pnas.1206820109

Mogedas AI \& Alameda JR. 2011. Toma de decisiones en pacientes drogodependientes. Adicciones 23:277-287.

Nusslock R \& Alloy LB. 2017. Reward processing and mood-related symptoms: An RDoC and translational neuroscience perspective. Journal of Affective Disorders 216:3-16. doi: 10.1016/j.jad.2017.02.001

Observatorio Español de la Droga y las Toxicomanías. 2015. Informe 2015. Alcohol, tabaco y drogas ilegales en España. Madrid: Ministerio del Interior.

Palacios E, Paíno S \& Alameda JR. 2010. Programa Cartas. Retrieved at http://www.uhu.es/jose.alameda/archivos/CartasSetup.jar el 2 de mayo de 2010

Polaina R, Moisa M, Opitz A, Grueschow M \& Ruff CC. (2015). The precision of value-based choices depends causally on fronto-parietal phase coupling. Nature Communications 6:8090. doi: 10.1038/natcomms/9090

Pope J, Gruber AJ, Hundon JL, Cohane G, Huestes MA \& Yurgelun-Todd D. 2003. Early-onset cannabis use and cognitive deficits: What is the nature of the association? Drug and Alcohol Dependence 69:303-310.

Rescorla RA \& Wagner AR. 1972. A theory of Pavlovian conditioning: Variations in the effectiveness of reinforcement and nonreinforcement. New York: Appleton-Century-Crofts.

Rolls ET. 2004. The functions of the orbitofrontal cortex. Brain and Cognition 55:11-29.

Schmitt WA, Brinkley CA \& Newman JP. 1999. Testing Damasio's somatic marker hypothesis with psychopathic individuals: Risk takers or risk averse? Journal of Abnormal Psychology 108:538-543.doi:10.1037/0021843X.108.3.538

Solowij N \& Battisti R. 2008. The chronic effects of cannabis on memory in humans: A review. Current Drug Abuse Reviews 1(1):81-98.

Solowij N, Stephens RS, Roffman RA, Babor T, Kadden R, Miller M, Christiansen K, McRee B, \& Vendetti J, 2002. 

Medical Association (JAMA) 287(9):1123-1131.

560

561

562

563

564

565

566

567

568

569

570

571

572

573

574

575

576

577

578

579

580

Solowij N, Yücel M, Respondek C, Whittle S, Lindsay E, Pantelis C, \& Lubman DI, 2011. Cerebellar white-matter changes in cannabis users with and without schizophrenia. Psychological Medicine 41(11):2349-2359.

Suzuki A, Hirota A, Takasawa N \& Shigemasu K. 2003. Application of the somatic marker hypothesis to individual differences in decision making. Biological Psychology 65:81-88. doi: 10.1016/S0301-0511(03)00093-0

Vélez AE, Borja KC \& Ostrosky-Solís F. 2010. Efectos del consumo de marihuana sobre la toma de decisión. Revista Mexicana de Psicología 27:309-315.

Volkow ND, Swanson JM, Evins AE, DeLisi LE, Meier MH, González R, Bloomfield MAP, Curran HV \& Baler R. 2016. Effects of cannabis use on human behavior including cognition motivation and psychosis: A review. The Journal of the American Medical Association (JAMA) Psychiatry 73(3):292-297. doi:10.1001/jamapsychiatry.2015.3278

Whitlow C, Liguori A, Brooke LL, Hart SL, Mussat-Whitlow BJ, Lamborn CM, Laurient P J \& Porrino LJ. 2004. Long-term heavy marijuana users make costly decisions on a gambling task. Drug and Alcohol Dependence 76:107-111.

Wilson W, Mathew R, Turkington T, Hawk T, Coleman RE \& Provenzale J. 2000. Brain morphological changes and early marijuana use: A magnetic resonance and positron emission tomography study. Journal of Addictive Disease 19:1-22.

Worthy DA, Pang B \& Byrne KA. 2013. Decomposing the roles of perseveration and expected value representation in models of the Iowa gambling task. Frontiers in Psychology 4:640. doi: 10.3389/fpsyg.2013.00640

Yechiam E, Busemeyer JR, Stout JC \& Bechara A. 2005. Using cognitive models to map relations between neuropsychological disorders and human decision making deficits. Psychological science 16(12):973-978. doi:10.1111/j.1467-9280.2005.01646.x 


\section{Table $\mathbf{1}$ (on next page)}

Gains-loss program and the probability of loss ( $p *$ ) of each deck in the IGT in a cycle of 10 plays. Decks A-B provide the highest short-term gains and the highest long-term losses (higher risk). Decks C-D provide little money at the short term but higher 


\begin{tabular}{llll}
\hline & \multicolumn{3}{l}{ Iowa Gambling Task (IGT) } \\
Deck & Gain & Loss & $\boldsymbol{p}^{*}$ \\
A (disadvantageous) & 100 & 150 & 0.5 \\
& & 300 & \\
& & 200 & \\
& & 250 & \\
& & & \\
B (disadvantageous) & 100 & 1250 & 0.1 \\
C (advantageous) & 50 & 25 & 0.5 \\
& & 25 & \\
& & 50 & \\
& & & \\
& & 75 & \\
D (advantageous) & 50 & 250 & 0.1 \\
\hline
\end{tabular}




\section{Table 2 (on next page)}

Descriptive and statistical analysis of the percentage of the number of selections from the advantageous decks in different blocks.

The $p$-value has been corrected by the Bonferroni adjustment for multiple comparisons. 


\begin{tabular}{|c|c|c|c|c|c|c|c|c|c|c|c|c|c|c|c|}
\hline & \multicolumn{3}{|c|}{ Early onset (EO) } & \multicolumn{3}{|c|}{ Late onset (LO) } & \multicolumn{3}{|c|}{ Control (C) } & \multicolumn{2}{|c|}{$\begin{array}{l}\text { EO-LO } \\
d f(1,34)\end{array}$} & \multicolumn{2}{|c|}{$\begin{array}{c}\text { EO-C } \\
d f(1,52)\end{array}$} & \multicolumn{2}{|c|}{$\begin{array}{c}\text { LO-C } \\
d f(1,52)\end{array}$} \\
\hline & $M$ & $S D$ & Range & $M$ & $S D$ & Range & $M$ & $S D$ & Range & $t$ & $p^{*}$ & $t$ & $p^{*}$ & & $p^{*}$ \\
\hline B1 & 26.39 & 15.32 & $10 / 55$ & 40.83 & 18.01 & $10 / 70$ & 43.61 & 16.15 & $10 / 80$ & 2.592 & .031 & 3.756 & .002 & 0.573 & 1 \\
\hline B2 & 35.28 & & $15 / 80$ & 46.94 & & $05 / 95$ & 59.44 & 19.45 & $00 / 100$ & 1.820 & .224 & 4.437 & .000 & 2.178 & .085 \\
\hline B3 & 28.61 & 15.51 & $05 / 65$ & 51.94 & 23.77 & 05/100 & 61.53 & 21.51 & $00 / 100$ & 3.488 & .004 & 5.774 & .000 & 1.490 & .346 \\
\hline B4 & 32.50 & 15.74 & $10 / 60$ & 55.00 & 18.79 & $35 / 100$ & 69.44 & 19.08 & $35 / 100$ & 3.895 & .001 & 7.088 & .000 & 2.636 & .023 \\
\hline B5 & 41.11 & 17.03 & $20 / 70$ & 55,56 & 17.17 & $30 / 85$ & 70.69 & 15.45 & $50 / 100$ & 2.291 & .057 & 6.411 & .000 & 3.571 & .002 \\
\hline
\end{tabular}




\section{Table 3 (on next page)}

Descriptive and statistical analysis of the PVL parameters

The $p$-value has been corrected by the Bonferroni adjustment for multiple comparisons 


\begin{tabular}{|c|c|c|c|c|c|c|c|c|c|c|c|c|c|c|c|}
\hline & \multicolumn{3}{|c|}{ Early onset (EO) } & \multicolumn{3}{|c|}{ ate onset (LO) } & \multicolumn{3}{|c|}{ Control (C) } & \multicolumn{2}{|c|}{$\begin{array}{l}\text { EO-LO } \\
d f(1,34)\end{array}$} & \multicolumn{2}{|c|}{$\begin{array}{c}\text { EO-C } \\
d f(1,52)\end{array}$} & \multicolumn{2}{|c|}{$\begin{array}{c}\text { LO-C } \\
d f(1,52)\end{array}$} \\
\hline & $M$ & $S D$ & Range & $M$ & $S D$ & Range & $M$ & $S D$ & Range & $t$ & $p^{*}$ & $t$ & $p^{*}$ & $t$ & $p^{*}$ \\
\hline & 0.69 & 0.38 & $0 / 1$ & 0.38 & 0.38 & $0 / 1$ & 0.41 & 0.39 & $0 / 1$ & 2.420 & .059 & 2.452 & .048 & 0.288 & 1 \\
\hline & 0.8 & & & & & & & & & & & & .00 & & .094 \\
\hline & 1 & 1.03 & $0.1 / 5$ & 1.57 & 1.39 & $0.1 / 5$ & 1.45 & 1.64 & $0.1 / 5$ & 1.399 & .727 & 1.047 & .887 & 0.279 & 1 \\
\hline & 0.03 & 0.05 & $0.1 / 0.22$ & 1.33 & 2.04 & $0.1 / 5$ & 2.72 & 1.94 & $0.1 / 5$ & 2.704 & $.07 /$ & 5.866 & .000 & 2.448 & .019 \\
\hline
\end{tabular}




\section{Table 4 (on next page)}

Descriptive and statistical analysis of the measurements recorded in each block of the reverse task.

The $p$-value has been corrected by the Bonferroni adjustment for multiple comparisons 
1

\begin{tabular}{|c|c|c|c|c|c|c|c|c|c|c|c|c|c|c|c|}
\hline & \multicolumn{3}{|c|}{ Early onset (EO) } & \multicolumn{3}{|c|}{ Late onset (LO) } & \multicolumn{3}{|c|}{ Control (C) } & \multicolumn{2}{|c|}{$\begin{array}{l}\text { EO-LO } \\
d f(1,34)\end{array}$} & \multicolumn{2}{|c|}{$\begin{array}{c}\text { EO-C } \\
d f(1,52)\end{array}$} & \multicolumn{2}{|c|}{$\begin{array}{c}\text { LO-C } \\
d f(1,52)\end{array}$} \\
\hline & $M$ & $S D$ & Range & $M$ & $S D$ & Range & $M$ & $S D$ & Range & $t$ & $p^{*}$ & $t$ & $p^{*}$ & $t$ & $p^{*}$ \\
\hline B1 & 46.39 & 17.81 & $25 / 100$ & 58.61 & 22.02 & $30 / 100$ & 46.53 & 22.32 & $0 / 100$ & 1.831 & .265 & 0.023 & 1 & 1.884 & .158 \\
\hline B2 & 44.17 & 16.11 & $0 / 65$ & 60.56 & 26.06 & $15 / 100$ & 50.28 & 30.26 & $0 / 100$ & 2.270 & .200 & 0.799 & 1 & 1.230 & .544 \\
\hline B3 & 35.83 & 17.17 & $0 / 60$ & 57.50 & 25.74 & $20 / 100$ & 52.08 & 29.87 & $0 / 100$ & 2.971 & .047 & 2.133 & .106 & 0.656 & 1 \\
\hline B4 & 41.94 & 19.19 & $10 / 80$ & 52.22 & 18.73 & $15 / 85$ & 46.67 & 30.71 & $0 / 100$ & 1.627 & .698 & 0.595 & 1 & 0.703 & 1 \\
\hline B5 & 42.78 & 14.58 & $0 / 65$ & 44.72 & 16.40 & $20 / 70$ & 51 & 28.15 & $0 / 100$ & 0.376 & 1 & 0.941 & 639 & 0.656 & 1 \\
\hline
\end{tabular}

2 


\section{Table 5 (on next page)}

Descriptive and statistical analysis of the PVL parameters in the reverse task.

The $p$-value has been corrected by the Bonferroni adjustment for multiple comparisons 
1

\begin{tabular}{|c|c|c|c|c|c|c|c|c|c|c|c|c|c|c|c|}
\hline & \multicolumn{3}{|c|}{ Early onset (EO) } & \multicolumn{3}{|c|}{ Late onset (LO) } & \multicolumn{3}{|c|}{ Control (C) } & \multicolumn{2}{|c|}{$\begin{array}{l}\text { EO-LO } \\
d f(1,34)\end{array}$} & \multicolumn{2}{|c|}{$\begin{array}{c}\text { EO-C } \\
d f(1,52)\end{array}$} & \multicolumn{2}{|c|}{$\begin{array}{c}\text { LO-C } \\
d f(1,52)\end{array}$} \\
\hline & $M$ & $S D$ & Range & $M$ & $S D$ & Range & $M$ & $S D$ & Range & $t$ & $p^{*}$ & $t$ & $p^{*}$ & $t$ & $p^{*}$ \\
\hline$\overline{\mathbf{A}}$ & 0.26 & 0.269 & $0 / 1$ & 0.47 & 0.35 & $0 / 1$ & 0.35 & 0.32 & $0 / 1$ & 2.058 & .133 & 1.108 & .878 & 1.250 & .589 \\
\hline$\alpha$ & 0.75 & 0.364 & $0 / 1$ & 0.63 & 0.43 & $0 / 1$ & 0.73 & 0.37 & $0 / 1$ & 0.913 & 1 & 0.114 & 1 & 0.973 & .979 \\
\hline c & 0.68 & 1.12 & $0 / 5$ & 0.93 & 1.13 & $0 / 4$ & 0.98 & 0.98 & $0 / 5$ & 0,655 & 1 & 0.994 & 1 & 0.165 & 1 \\
\hline$\lambda$ & 3.04 & 2.15 & $0 / 5$ & 2.33 & 2.09 & $0 / 5$ & 2.22 & 2.15 & $0 / 5$ & 1,008 & 1 & 1.318 & .568 & 0.169 & 1 \\
\hline
\end{tabular}

2 
Figure 1

Screenshot of the Cards program
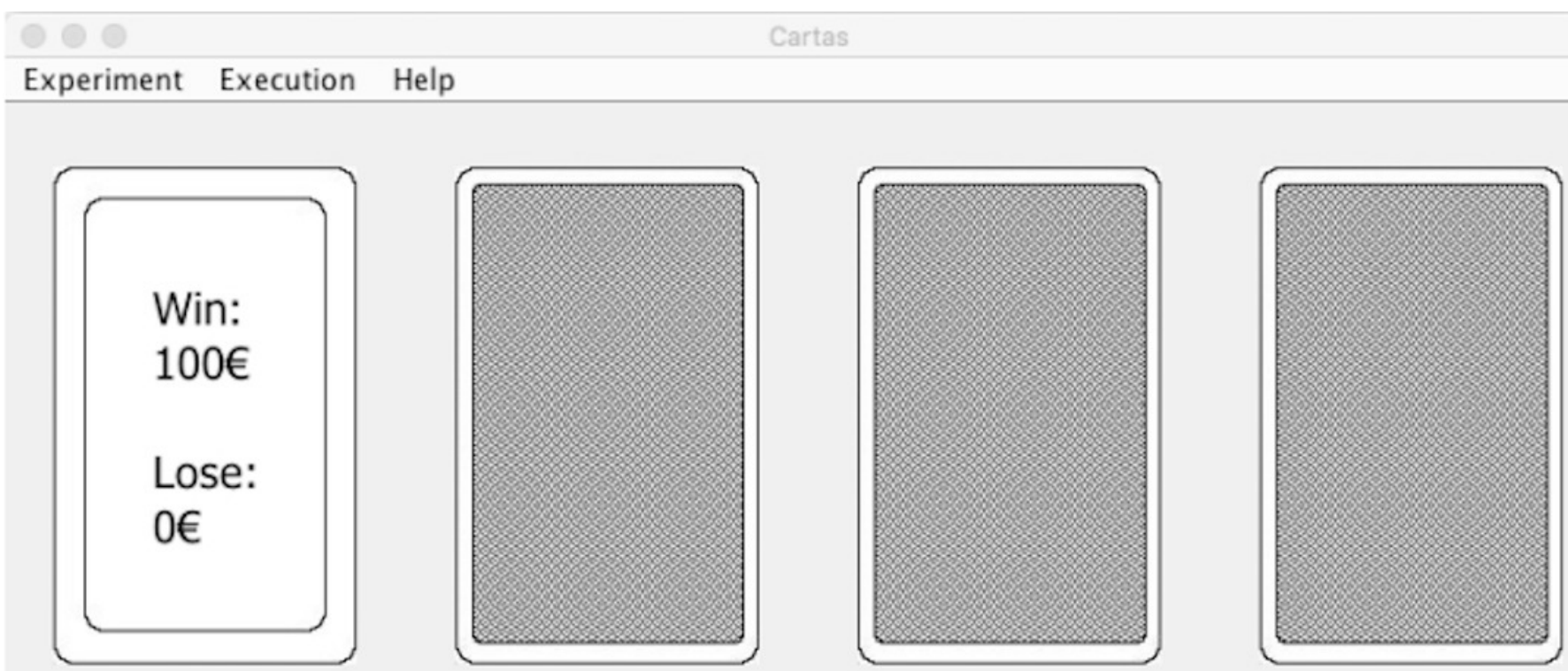

\section{Balance: $2100 €$}


Figure 2

Graph of advantageous/disadvantageous choices in total task

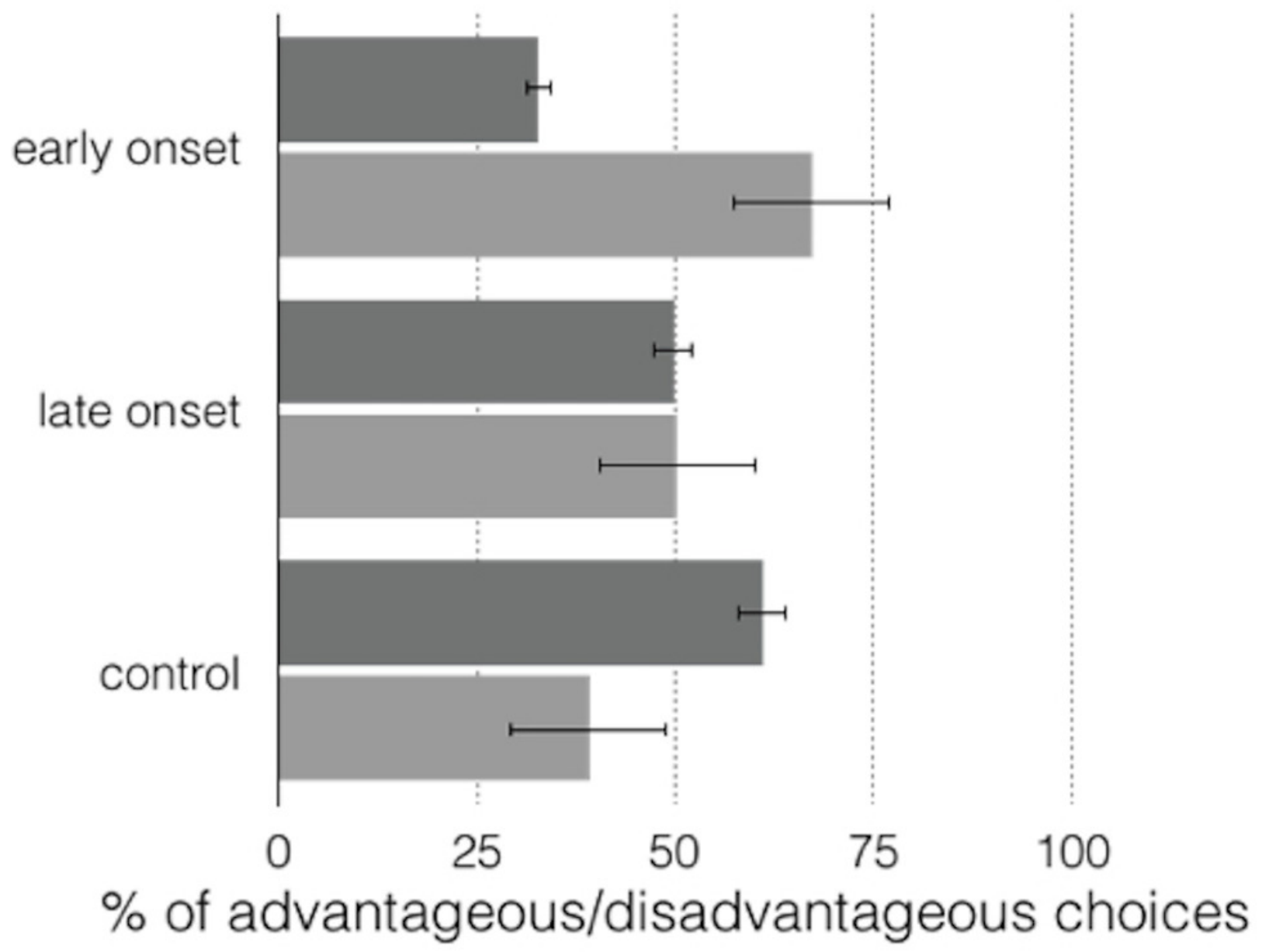

\section{Advantageous choices}

Disadvantageous choices 
Figure 3

Graphic representation of the advantageous choices across the blocks
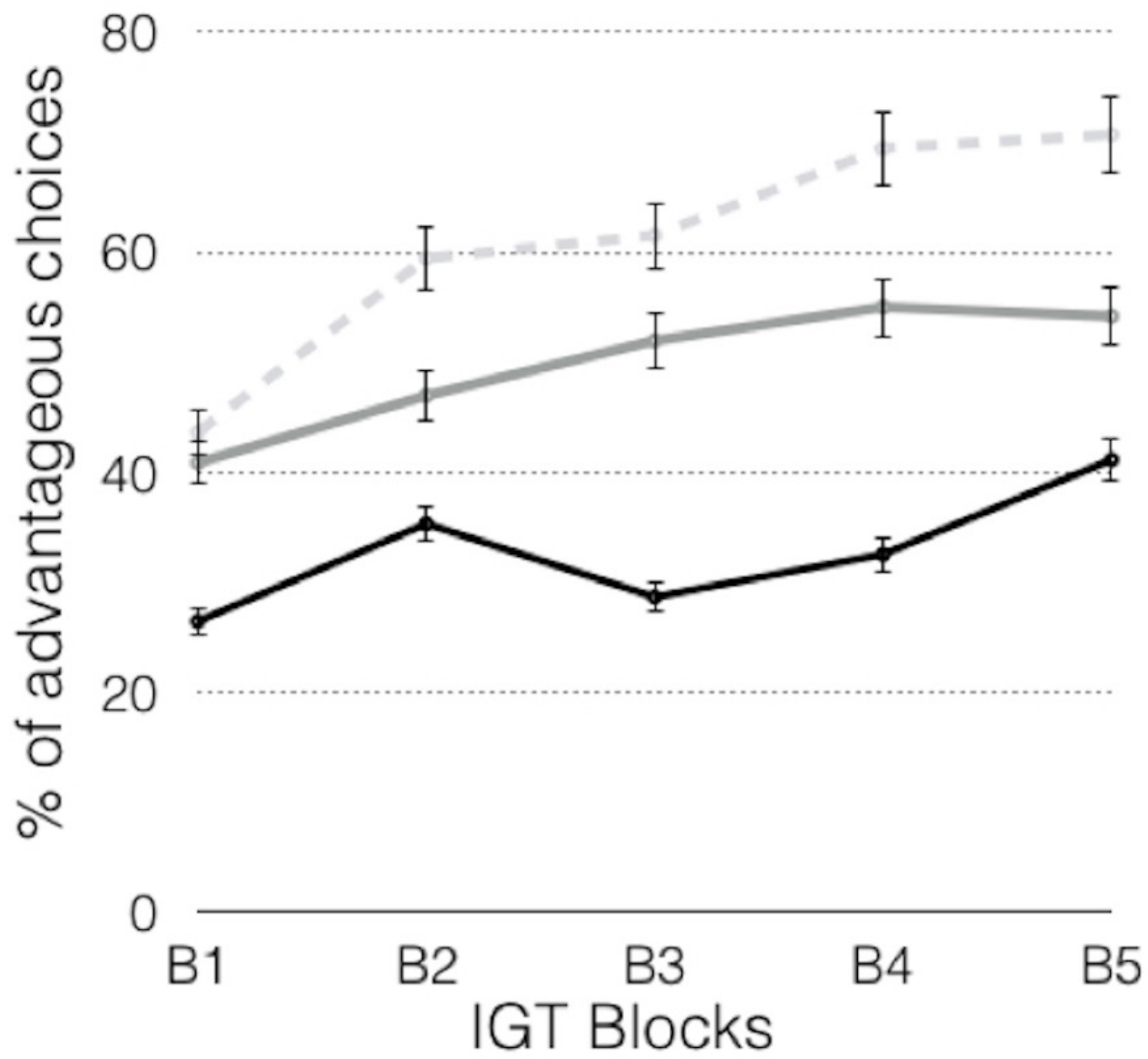

- Early onset $\circ$ Late onset $\circ$ Control 
Figure 4

Graphic representation and mean differences of PVL model parameters in the three groups of participants

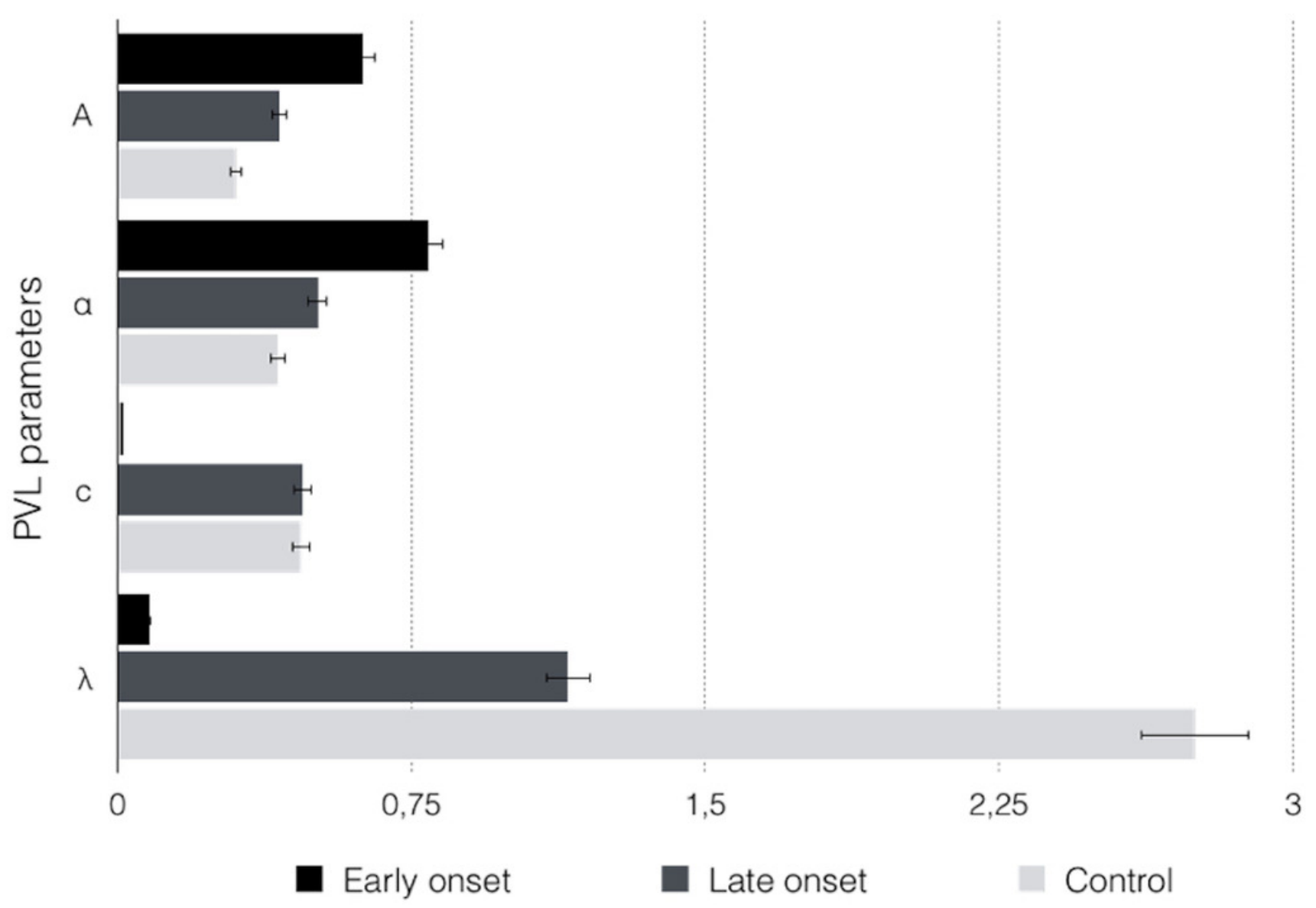


Figure 5

Advantageous choices across the inverse task

100

0
0
0
0
0
0
0
2
0
0
0
$\frac{1}{ \pm}$
$\frac{1}{0}$
0
0
0
0

75

๑

芩 50

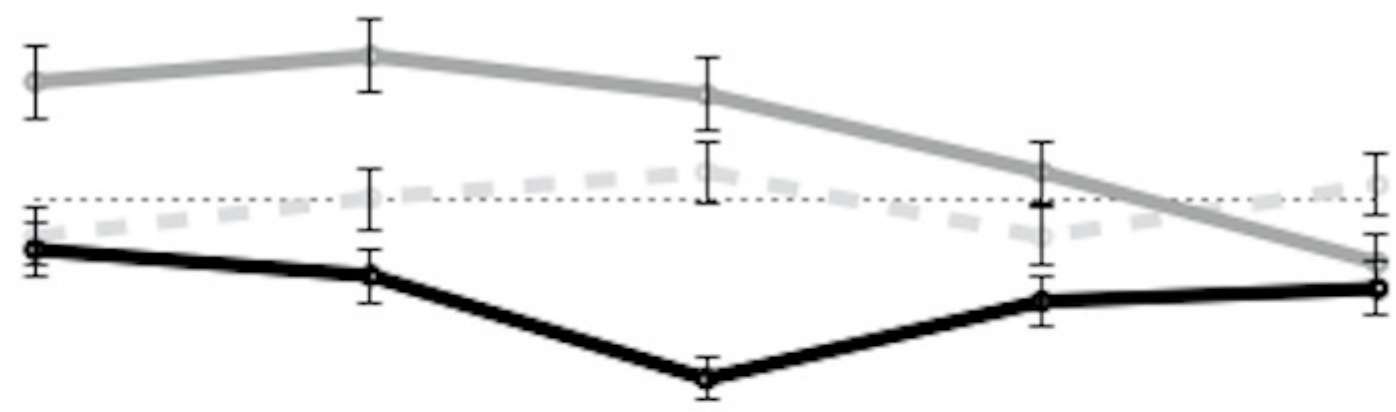

25

0

B1

B2

B3

B4

B5

Blocks

- Early onset

- Late onset

Control 
Figure 6

Response latency in Advantageous choices (A) and Disadvantageous choices (B) across the inverse task

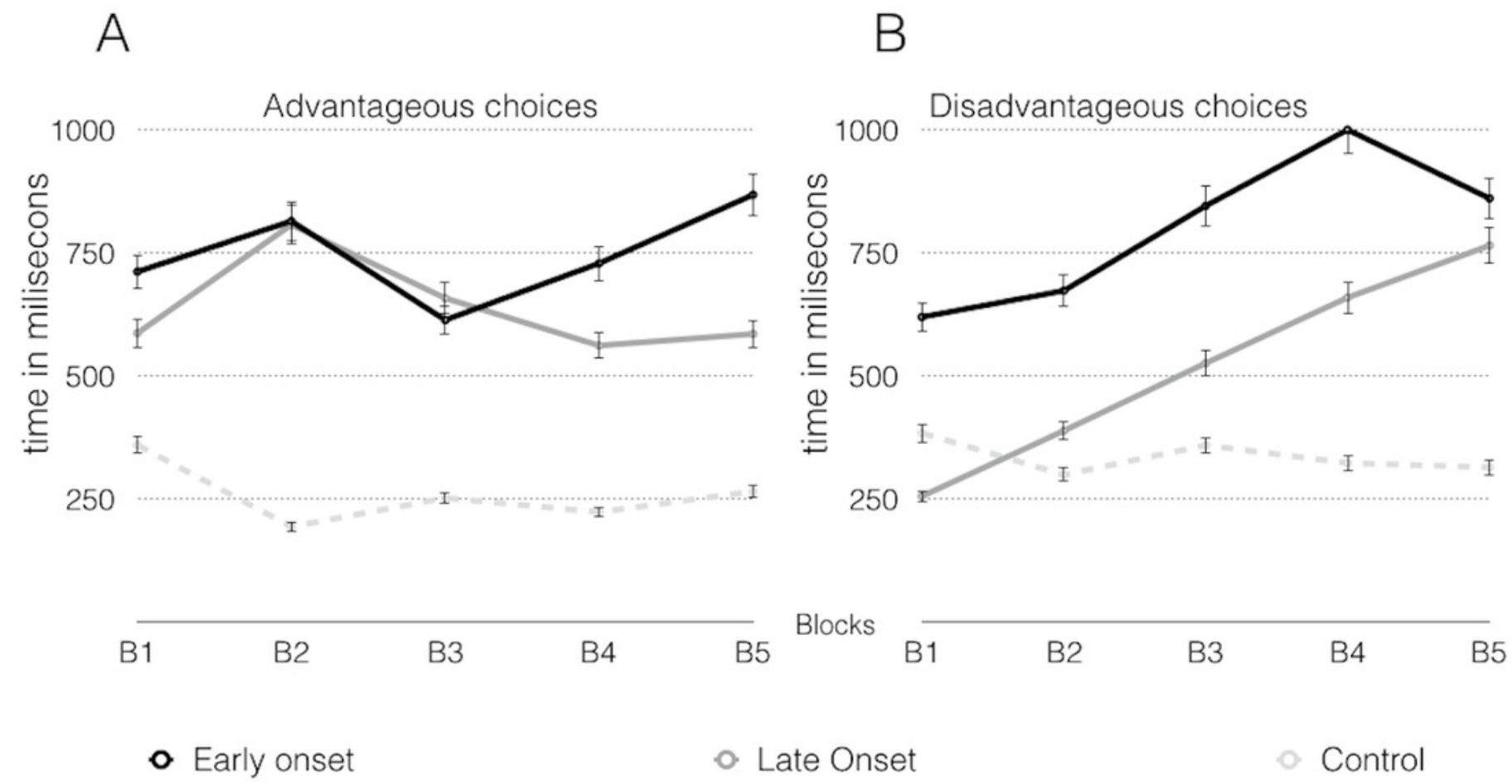

